University of South Carolina

Scholar Commons

$9-2005$

\title{
Paradox and the Consumption of Authenticity through Reality Television
}

Randall L. Rose

University of South Carolina - Columbia, roser@moore.sc.edu

Stacy L. Wood

wood@moore.sc.edu

Follow this and additional works at: https://scholarcommons.sc.edu/mark_facpub

Part of the Marketing Commons

Publication Info

Journal of Consumer Research, Volume 32, Issue 2, 2005, pages 284-296.

http://jcr.wisc.edu/

(C) 2005 by Journal of Consumer Research, Inc.

This Article is brought to you by the Marketing Department at Scholar Commons. It has been accepted for inclusion in Faculty Publications by an authorized administrator of Scholar Commons. For more information, please contact digres@mailbox.sc.edu. 


\title{
Paradox and the Consumption of Authenticity through Reality Television
}

\author{
RANDALL L. ROSE \\ STACY L. WOOD*
}

\begin{abstract}
We position reality television within the broader category of consumer practices of authenticity seeking in a postmodern cultural context. The study draws on relevant perspectives from consumer research, literary criticism, sociology, and anthropology to argue that viewers of reality television encounter three elements of paradox in the process of constructing authenticity. The negotiation of each paradox exceeds the process of coping with or resolving their inherent contradictions to encompass the creation of new values. We argue that consumers blend fantastic elements of programming with indexical elements connected to their lived experiences to create a form of self-referential hyperauthenticity.
\end{abstract}

$\mathrm{R}$ eality television programming has recently materialized in the national consciousness. The startling success of such shows as The Apprentice, Survivor, The Bachelorette, and even PBS's Frontier House represent only the most visible of a surprising plethora of reality-based programming (see table 1 for a sample of recent cable channel offerings). Although such fare has never been so prominent, the origins of the genre include MTV's infamous progenitor The Real World, as well as earlier radio and print media (Calvert 2000). The breadth of the reality programming phenomenon is also reflecte in two major motion pictures, The Truman Show and Ed TV, each of which addresses the blurring of boundaries between real life and entertainment. The voyeuristic aspects of such fare are famously evoked in Hitchcock's classic drama Rear Window, whose depiction of the passive, ignominious voyeur dominates the popular press and scholarly criticism of the reality programming genre (e.g., Abelman 1998; Bork 1996).

Faced with the commonplace criticism of reality television viewers as passive voyeurs, however, we fin more insightful perspective on the phenomenon in Boorstin's (1961) conclusion that life has become stagecraft - a blending of reality and mass mediated experience that evokes life as a movie in which people play themselves (Gabler 1998). As we will argue, the consumption of reality programming represents a sophisticated quest for authenticity within the traditionally fiction-oriente entertainment paradigm. Re-

*Randall L. Rose is professor of marketing (e-mail: roser@moore.sc .edu), and Stacy L. Wood is associate professor of marketing (e-mail: wood@moore.sc.edu), both in the Moore School of Business, University of South Carolina, Columbia, SC 29208. Correspondence: Randall L. Rose. The authors contributed equally to this research. The authors acknowledge the helpful input of June Cotte, David Crockett, Colbey Emmerson, David Wooten, the editor, associate editor, and three very constructive reviewers. ality television ratings increase despite the availability of alternative "real" programming such as CSPAN or cable news or historical biographies. In contrast to news programs, however, the majority of reality fare depicts common people engaging in uncommon (wilderness survival, international travel) and common (dating, home redecorating) tasks, giving viewers the chance to compare and contrast their own lives with those of the show's "protagonist." Our data suggest that reality television does not represent simple entertainment. Our research is guided by an attempt to answer the following question regarding the consumption of authenticity, using reality television as the focal domain of practice: What, if anything, can reality television viewers tell us about the consumption of authenticity in a cultural context increasingly characterized by simulation? In answering this question we address broader theoretical issues relevant to consumption practices, especially those concerning the meaning of authenticity and the attraction of authenticity to the postmodern consumer.

\section{THEORETICAL BACKGROUND}

What is authentic? Trilling's (1972) view of the authenticity of an object as a function of perceived genuineness and positive valuation has closely informed the limited consumer research dedicated specificall to its explication. Adopting a semiotics perspective, Grayson and Shulman (2000) explain the genuineness and irreplaceable character of special possessions in terms of their indexicality. That is, irreplaceable possessions are seen as indexes "because they have a factual, spatial connection with the special events and people they represent" (Grayson and Shulman $2000,19)$. The connectedness of objects to highly valued elements of consumers' lived experience grounds judgments 
TABLE 1

REALITY SHOWS

\begin{tabular}{|c|c|c|}
\hline Channel & Show & Description \\
\hline \multirow[t]{3}{*}{$A B C$} & Bachelor/Bachelorette & Opposite sex competes for affection of another \\
\hline & The Mole & $\begin{array}{l}\text { Sixteen people travel Europe and engage in espionage-style challenges } \\
\text { in an attempt to discover which of their colleagues is a counterspy }\end{array}$ \\
\hline & Extreme Makeover & $\begin{array}{l}\text { Individuals who lack confidenc in their physical appearance get plastic } \\
\text { surgery and other help before returning home }\end{array}$ \\
\hline \multirow{3}{*}{ ABC Family } & Amp Up Your Room & Teen and preteen version of room makeover \\
\hline & My Life as a Sitcom & $\begin{array}{l}\text { Families compete for the network's attention to prove that their family is } \\
\text { worthy of sitcom material }\end{array}$ \\
\hline & Switched & $\begin{array}{l}\text { Two contestants switch jobs, families, and lifestyles to see how the other } \\
\text { lives }\end{array}$ \\
\hline \multirow[t]{2}{*}{ Animal Planet } & King of the Jungle & $\begin{array}{l}\text { Biologists, vets, and other animal experts compete to win a job as an An- } \\
\text { imal Planet TV host }\end{array}$ \\
\hline & Animal Precinct & $\begin{array}{l}\text { Follow the daily lives of animal control officer as they combat animal } \\
\text { cruelty in the United States }\end{array}$ \\
\hline \multirow[t]{3}{*}{$A \& E$} & Sell This House & $\begin{array}{l}\text { This Old House and Candid Camera meet to get inside the mind of the } \\
\text { buyer and the heart of a seller }\end{array}$ \\
\hline & House of Dreams & $\begin{array}{l}16 \text { neighbors collaborate to plan, design, and build a home that only one } \\
\text { will possess at the end }\end{array}$ \\
\hline & Airline & $\begin{array}{l}\text { Follow the interesting actions that go on behind the scenes of Southwest } \\
\text { Airlines }\end{array}$ \\
\hline \multirow[t]{3}{*}{ BBC America } & $\begin{array}{l}\text { The Life Laundry } \\
\text { Changing Rooms }\end{array}$ & $\begin{array}{l}\text { Cleaning up and organizing not only one's life but inner self as well } \\
\text { Home makeover; original version of Trading Spaces }\end{array}$ \\
\hline & Faking It & Novices learn a new trade to compete with experts to test their skills \\
\hline & Ground Force & Landscaping makeover competition \\
\hline \multirow[t]{4}{*}{ CBS } & Survivor & Teams compete in exotic locales \\
\hline & Amazing Race & $\begin{array}{l}\text { Teams of two race across continents to test their physical, mental, and } \\
\text { relationship abilities }\end{array}$ \\
\hline & Big Brother & $\begin{array}{l}\text { Individuals locked in a house away from the outside world test their so- } \\
\text { cial skills }\end{array}$ \\
\hline & Cupid & $\begin{array}{l}\text { Woman and two girlfriends search the United States for her perfect } \\
\text { match }\end{array}$ \\
\hline CMT & Cowboy & People learn what it takes to become professional cowboys \\
\hline \multirow[t]{2}{*}{ Discovery Channel } & Monster Garage & Crew of experts is assembled to build off-the-wall vehicles \\
\hline & American Chopper & $\begin{array}{l}\text { Members of a small family motorcycle business are watched in their hos- } \\
\text { tile daily lives }\end{array}$ \\
\hline \multirow[t]{2}{*}{ ESPN } & Dream Job & Wannabe sports announcers compete for a job at the network \\
\hline & Beg, Borrow, and Deal & $\begin{array}{l}\text { Teams compete to race across the United States while accomplishing } \\
\text { sports-related tasks }\end{array}$ \\
\hline \multirow[t]{2}{*}{ Fox } & Temptation Island & $\begin{array}{l}\text { Four committed but unwed couples are sent to an island resort where } \\
\text { they are separated and spend time in the company of attractive singles } \\
\text { to test their commitment }\end{array}$ \\
\hline & The Simple Life & $\begin{array}{l}\text { Two of Hollywood's most pampered teens live with a farm family in rural } \\
\text { Arkansas }\end{array}$ \\
\hline Golf Channel & The Big Break & $\begin{array}{l}\text { A group of low-handicapped golfers compete for a spot on a Canadian } \\
\text { tour }\end{array}$ \\
\hline \multirow[t]{2}{*}{ MTV } & Real World & $\begin{array}{l}\text { Young adults live in one home and act together in a business venture; } \\
\text { cameras allowed full access }\end{array}$ \\
\hline & Newlyweds & $\begin{array}{l}\text { Two of the popular music industry's newlyweds are followed in their daily } \\
\text { lives }\end{array}$ \\
\hline \multirow[t]{4}{*}{ National Geographic } & Worlds Apart & $\begin{array}{l}\text { Common American families spend time with another native family of a } \\
\text { third-world origin }\end{array}$ \\
\hline & The Apprentice & Competitors vie for a spot as Donald Trump's personal apprentice \\
\hline & The Restaurant & $\begin{array}{l}\text { Follow the daily happenings of one of New York's top chefs as he opens } \\
\text { up a restaurant }\end{array}$ \\
\hline & Who Wants to Marry My Dad & Offspring interview suitors to date their dad \\
\hline \multirow[t]{2}{*}{ PBS } & Frontier House & Three families experience the real life of 1883 Montana \\
\hline & Colonial House & New series to come \\
\hline \multirow[t]{2}{*}{ SPIKE TV } & Joe Schmo Show & $\begin{array}{l}\text { A man believes he is competing with others in a bizarre reality show, } \\
\text { only to fin that all the others are actors }\end{array}$ \\
\hline & Blind Date & Couples are arranged and observed on dates \\
\hline \multirow[t]{5}{*}{ TLC } & Baby Story & Personal footage of a couples' birthing experience \\
\hline & Wedding Story & Personal footage of a couples' wedding experience \\
\hline & Trading Spaces & Two families work on each others' homes \\
\hline & Clean Sweep & Experts help family clean out their house clutter \\
\hline & In a Fix & Professional contractors save an amateur's home renovation gone awry \\
\hline
\end{tabular}


TABLE 1 (Continued)

\begin{tabular}{|c|c|c|}
\hline Channel & Show & Description \\
\hline $\begin{array}{l}\text { UPN } \\
\text { WB }\end{array}$ & $\begin{array}{l}\text { Protect and Serve } \\
\text { Second Chance } \\
\text { While You Were Out } \\
\text { What Not To Wear } \\
\text { For Better or for Worse } \\
\\
\text { Junkyard Wars } \\
\text { Americas Next Top Model } \\
\text { The Surreal Life }\end{array}$ & $\begin{array}{l}\text { Daily lives of America's police force } \\
\text { Dating show of reuniting with past acquaintances } \\
\text { Home makeover before a member of the household returns } \\
\text { Fashion experts take control over one's fashion faux pas } \\
\text { Friends and family control all areas of a couple's wedding planning on a } \\
\text { budget } \\
\text { Teams compete to build machines out of scrap material } \\
\text { Attractive individuals compete for exposure } \\
\text { Has-been stars share a home and are expected to perform outrageous } \\
\text { acts (Erik Estrada, Vanilla Ice, Tammy Faye) }\end{array}$ \\
\hline
\end{tabular}

of authenticity in the "real" world and suggests that consumers can readily distinguish between the authentic and the factitious. Grayson and Shulman's perspective sharply contrasts postmodern views of hyperreality in which simulation is substituted for genuine experience, and perhaps even preferred (Baudrillard 1983).

Philosophically, the drive for authenticity may be conceived as a reaction to threats of inauthenticity inherent in postmodernism (Firat and Venkatesh 1995). The ravages of inauthenticity (e.g., the sense of a meaningless, superficial or performative existence) have been a common theme in literary and philosophical works since the late nineteenth century (e.g., Flaubert, Sartre, Nietzsche). In the environment of plastic humanity, only "the poor, the oppressed, the violent, and the primitive" were credited as real (Trilling 1972, 102). The success of reality-based entertainment may be a reflectio of the modernists' nostalgia for authenticity among the class of consumers to whom it is most rigorously denied. The exaltation of the commonplace in programming that replaces celebrities with average citizens (e.g., Cops or Big Brother) could be viewed as an echo of modernist angst. What Bourdieu (1980) has labeled a popular aesthetic distinctly opposes the bourgeois ideology of mass culture by affi ming the personable, subjective, and malleable nature of objects. The popular aesthetic empowers consumers of mass culture to defend the pleasure they obtain from it.

Thus, consumers increasingly value authenticity in a world where the mass production of artifacts causes them to question the plausibility of the value. Consider, for example, the domain of primitivism, a modernist movement popularized by Pablo Picasso involving the collection and idealization of African craft work. Some contemporary collectors posit that the authenticity of an artifact resides not only in the proper creation of a piece (i.e., crafted by an individual who belongs, by birth, to the tribe of provenance) but also in the purpose motivating its creation (Cornet 1975). Thus, collectors may ascribe more value to pieces crafted for personal use. That a collected piece is, by the act of collection, necessarily bought and sold (irrespective of the maker's original intention) is irrelevant in this machination of cultural reality. Others, however, embrace the evolving modification of tribal craft due to commercial discourse, deeming artifacts that depart from tribal traditions to accommodate market demands as sociologically valid and au- thentic (Hedges 1997). Thus, collectors dispute what constitutes "real" and yet, ultimately, disparate views must converge in the fixatio of market value.

Similarly, tourists can be categorized according to the centrality of authenticity as a motivation of their travel behavior. Cohen (1979) describes fiv kinds of tourists: (1) existential - those who are strict authenticity seekers, (2) experimental - those who seek authenticity but are less committed in the face of difficult in attainment, (3) experiential-those who seek to participate in some aspect of authentic life of visited culture, (4) recreational - those who approach cultural products with a playful "make believe" attitude, and (5) diversionary - those who are completely unconcerned with authenticity. Cohen also suggests that travelers are able to accept their experience as authentic, despite the evident existence of a tourist trade, because to them the experience was "as real as possible." As consumers of travel experiences, most tourists are capable of reconciling the real and unreal parts of their trip. In such instances, they may choose to ignore indications of mass production in the souvenir craft work they purchase or to turn a blind eye to the multiple tour buses parked outside an attraction touted as "off the beaten path."

Thus, within the apparent obsession with authenticity lies a postmodern paradox. Although authenticity is desired and earnestly promoted, consumers of reality television revel in the ironic mixture of the factitious and the spontaneous. Similar observations have been made in other contexts. For example, Urry (1990) uses the label "posttourists" to refer to postmodern consumers who fin the blending of stagecraft and local culture to be a desirable aspect of the touristic experience, and Feifer (1985) refers to those consumers who relish the simulation inherent in postmodern shopping environments as postshoppers. Such practices led Baudrillard (1983) to identify the modern person as one concerned with a signifie reality in addition to reality itself and suggested to Orvell (1989, xxiii) that an appropriate label for the postmodern era is "a culture of the factitious." It may matter less whether programs such as Survivor are real in some objective sense than that the subjective experience of reality involves the complex interaction of message and audience. Baudrillard's perspective is perhaps best exemplifie in the consumer research literature by the work of Ritson and Elliot (1999). Although their research focuses on the centrality 
TABLE 2

LIST OF INFORMANTS

\begin{tabular}{|c|c|c|c|c|c|}
\hline Pseudonym & Age & Family status & Profession & Race & Reality show \\
\hline Shirley & Early 20s & Single, no children & College student & $\mathrm{C}$ & Survivor II \\
\hline Elizabeth & Early 20 s & Single, no children & College student & $\mathrm{C}$ & Temptation Island \\
\hline Tonya & Late 30 s & Divorced, no children & Graduate student & $\mathrm{C}$ & Survivor II \\
\hline Blake & Early 20 s & Single, no children & College student & C & Survivor II \\
\hline Pam & Early 40 s & Married, two children & $\mathrm{K}-12$ teacher & $\mathrm{C}$ & Temptation Island \\
\hline Lola & Mid-50s & Married, empty nest & Executive secretary & $\mathrm{C}$ & The Mole \\
\hline Priscilla & Early 40 s & Married, one child & Offic manager & $\mathrm{C}$ & Temptation Island \\
\hline Judy & Early 30 s & Single, no children & State energy planner & $\mathrm{C}$ & Survivor II \\
\hline Gina & Early 30 s & Single, no children & Purchasing office & C & Survivor II \\
\hline Robin & Late 20 s & Single, no children & Graphic artist & $\mathrm{C}$ & Temptation Island \\
\hline Dan & Early 20s & Single, no children & College student & $\mathrm{C}$ & Temptation Island \\
\hline Calvin & Mid-40s & Married, children & Grant administrator & $\mathrm{C}$ & The Mole \\
\hline Monica & Mid-30s & Married, no children & Director of admissions & $\mathrm{C}$ & The Mole \\
\hline Charles & Mid-30s & Married, two children & Network administrator & $\mathrm{AA}$ & The Mole \\
\hline Larry & Early 20 s & Single, no children & College student & C & Survivor II \\
\hline
\end{tabular}

NotE.-C denotes Caucasian; AA denotes African American.

of advertising to everyday life and its social uses by consumers, the notion that the audience actively negotiates meaning from an advertising text is directly applicable to other media, including reality television.

The notion of consumers as producers of meaning seems useful to our understanding of authenticity. Arnould and Price (2000) denote the central role of authenticity seeking in everyday consumer practice as a response to the fragmentation and alienation elicited by postmodern cultural forces (Baudrillard 1983; Firat and Venkatesh 1995). Driven to authenticate the self and important social spaces, consumers engage in authenticating acts and authoritative performances. Authenticating acts are those "self-referential behaviors actors feel reveal or produce the 'true' self," such as flo experiences while skydiving (Celsi, Rose, and Leigh 1993) and ritualistic display of paraphernalia and body alteration by members of the English punk subculture (Widdicombe and Wooffit 1990). Authoritative performances are "collective displays aimed at inventing or refashioning cultural traditions" (Arnould and Price 2000, 140), such as the antiglobalization, antibranding practices exhibited en masse during the Burning Man festival as interpreted by Kozinets (2002).

Although space limitations preclude a detailed review of all the consumer practices related to authenticity, it is important to note that little research attention has been directed toward understanding how consumers negotiate the authentic in a culture based increasingly on simulation (Firat and Venkatesh 1995). Arnould and Price's (2000) discussion of the quest for authenticity, papers by Deighton and colleagues (Deighton 1992; Deighton, Romer, and McQueen 1989) on the consumption of drama and performance, and Stern's (1994) exploration of authenticity in advertising stand as noteworthy exceptions. These works provide an important starting point for understanding audience responsiveness to reality programming. In particular, they suggest that authenticity may be constructed through viewer practices and that it is meaningful only in cultural context. From this point, we turn to the current data in which we investigate the relevance and explanatory power of theoretical notions of authenticity in the context of consumers' accounts of reality television viewing. Here we look to see if reality television is perceived as uniquely authentic and, if so, how viewers cope with elements of fantasy and simulation within the programming.

\section{METHOD}

Our primary data were text derived from depth interviews with 15 reality television viewers (table 2 ) and their journals. In the journals, participants recorded their thoughts, feelings, and experiences while viewing at least one of three reality television programs that aired during the 2000-2001 American television season. Participants chose a program to watch or were assigned to one if they expressed no preference. Six participants watched Survivor II, while four each watched Temptation Island or The Mole. Although the journals were focused on one program, the long interview format explored the meanings consumers derived through viewing reality programs and other forms of authenticity seeking in a broader context. In addition, two informants were interviewed a second time $1 \mathrm{yr}$. after the initial interview. These data were supplemented by the researchers' tracking of Internet sites devoted to each program, reading Internet message boards related to some of the programs, and careful scrutiny of entertainment media for related commentary. These activities provided context for understanding informants' accounts.

\section{NEGOTIATING THE REAL}

From our analysis of audience accounts we find most generally, that reality programming is viewed as a mix of authentic and inauthentic elements. However, satisfying au- 
thenticity is a function of successfully negotiating the paradoxes inherent in the genre-a reconciliation of the tensions between what is subjectively real and fantastic.

Thus, there emerged an understanding of the audience as involved in a reflexiv negotiation of personal authenticity; this relationship serves as the basis for our conceptual framework (fig 1). The negotiation process observed utilized inputs from a variety of marketer controlled, wider cultural, and personal texts and was characterized specifically by the reconciliation of three main paradoxes that emerge as inherent to the reality programming genre. These paradoxes encompass (1) situation, (2) identification and (3) production. We firs turn to a discussion of these themes as they appear in the data.

\section{The Paradox of Situations}

Ostensibly, one of the more important and appealing aspects of reality television programming is the genuine nature of the program context. Our data indicate that the situationbased meanings derived by consumers from watching reality television are not simplistic but rather reflec a sophisticated negotiation of paradoxical elements. In their responses, we see the appreciation of explicitly fantastic elements of the situation and resonance with implicit self-relevant themes and tasks. First, Larry illustrates the appreciation of fantasy:

Larry: I still think the firs [Survivor] wins on cool points because the whole "stranded on an uninhabited island" theme is something I think most people have fantasized about. Just being out on your own on the beach. It just sounds cooler than being in Australia. Australia just doesn't sound exotic or tropical. It sounds dull and rough. (From his journal)

Satisfying authenticity is a function of the conjunction of the objectively real and the desirable. Personally attractive, albeit foreign, environments enhanced viewers' appreciation for the programming context. Calvin's com-

FIGURE 1

CONSTRUCTING AUTHENTICITY THROUGH REALITY TELEVISION

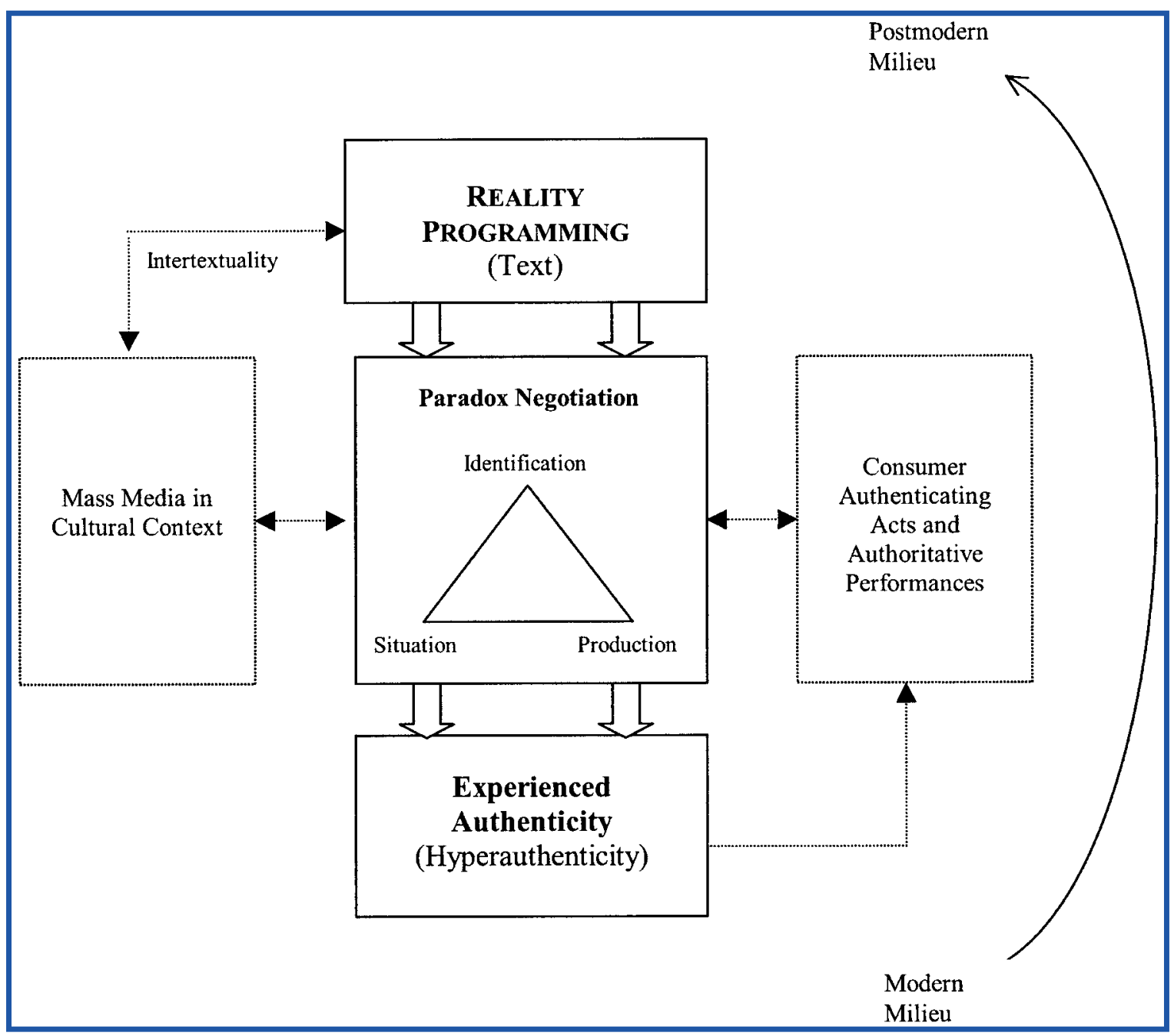


ments about The Mole illustrate hedonic appreciation of the exotic setting:

Calvin: I loved the location. It's not like Survivor where you have to go to the outback, on a desert island, eat rats, and cook food, although that has its entertainment value as well. But, these guys stayed in five-sta hotels in Spain and France and ate grapefruit. That's great.

Thus, turning fantasy into an authentic experience may be more desirable than turning the authentic experience into the fantastic. Both Australia and a tropical island are real and equally foreign to Larry's direct experience. However, he prefers the tropical island "paradise" to the Australian outback due to preconceived, socially constructed notions of what the experience of each is like. Paradise commonly takes the island form (whether lampooned in Gilligan's Island or sacralized in The Blue Lagoon), perhaps due to the salient physical separation from a more mundane mainland. Larry cites explicitly in his interview a recent film Castaway, to explain his attraction to an escapist fantasy. Interestingly, after two seasons of roughing it in Australia and Africa (with declining ratings), Survivor returned to paradise (a South Pacifi island) in 2002 and has remained island based in subsequent seasons. To wit, although Gina reported enjoying most reality shows, she rejected Big Brother as "too real."

Gina: I couldn't sit through Big Brother. It was just too "oh, we're sitting around on the couch" and that was too real. [Interviewer: How so?] I mean . . . I mean it was live and you saw people doing what they normally do. Sitting on the couch, going to get something to eat, or, well, you know, "we'll go sit out in the yard." . . . It was too real. I mean, there's a line between, you know, true reality and reality that's entertaining.

To Gina, entertainment value resided in the program's provision of a situation that was beyond the viewer's daily "real" life. Yet, on a deeper level, many participants looked beyond superficia fantastic elements of the show and saw problems, tasks, and goals similar to or symbolic of their day-to-day lives:

Larry: It's in situations that we sometimes cope with. You know, I don't guess anyone's gonna get stranded in the outback or anything. But, I mean, it's the same type of reactions. We might argue over other stuff than rice.

Dan: It was just kinda real life reactions and situations.

Interviewer: So a real life situation?

Dan: Not so much that, you know, you're not going to be going on dates to these exotic places, but you're going to be tempted . . . whether it be in the workplace or at school.

Similarly, despite the "fantastic" opulence of the environment and the contrivance of the "games," Calvin still per- ceives a self-relevant authenticity in the situational structure of The Mole.

Calvin: The show is actually more of a Survivor show than Survivor for the simple reason that the players control their own fate. They vote themselves off by not answering questions correctly. On Survivor, everyone votes you off on peer evaluations. So, on The Mole you have more control over your own fate. Either you're right or you're wrong. I don't care how much other people hate you or don't like the way you dress. As long as you answer the questions right, you stay on the show. That is one of the best reasons I liked the show. . . . I like Survivor, don't get me wrong, but The Mole is more reality based in concept, in my opinion, than any other reality show.

Calvin discussed the intellectual challenge of actual and vicarious participation in The Mole and the fact that the winner not only had to guess who the mole was but also remember minute details about the participants. Calvin's preference for The Mole over Survivor can be explained in part by the ability of the program context to facilitate, reinforce, and signify his important life goals and experiences. He used to work in intelligence for the military but never got the chance to root out any real "moles." The preferences of other viewers were similarly constructed but referred to different goals and themes. Tonya liked Boot Camp because she always wanted a military career. She saw the challenges on Boot Camp as more "real and rewarding."

This paradoxical combination of desired fantasy and selfreferenced goals is intriguing in both the viewer's apparent ease in negotiation and the influenc successful negotiation has on the viewer's attraction to the program. For instance, Priscilla and Pam both rejected Temptation Island, not because they didn't enjoy the fantasy of the locale, but because they perceived the goals of the "characters" as not genuine and inconsistent with personal standards of conduct.

Pam: I didn't get involved with any of the characters. It didn't faze me if they left and went home. . . . When the players firs came in I thought they were married. I knew nothing about the show. I thought married couples doing that was the worst thing I could think of. Then I realized it was singles, which made it somewhat better. But, once you're married, I wouldn't think you would want to get tempted. You should have done that before.

When viewers could negotiate situational duality, findin self-relevant goals/tasks in an entertaining fantasy locale, they evidenced the strongest enjoyment of the reality program. We believe this association between daydreaming, imagination, and pleasure speaks to Campbell's $(1987,90)$ argument that "in modern hedonism pleasure is not simply a quality of experience, but a self-illusioned quality of experience. Increasingly pleasure is a commodity associated with experiences which we have had a hand in constructing; something which we have 'tailored' to suit our own needs." Campbell's framework of the interaction between illusion and direct experience serves as a strong foundation from 
which to view the paradox of situation. In his framework, many products are consumed because "they serve as aids to the construction of daydreams" $(1987,92)$. Reality television programs provide settings and contexts consonant with consumers' daydreams and imaginations. Their popularity can, in part, be explained by Campbell's central insight that consumers "do not so much seek satisfaction from products, as pleasure from the self-illusory experiences which they construct from their associated meanings" (1987, 89). Audiences fin the settings and situations of reality television programming novel enough to be stimulating yet familiar enough to permit an imaginary participation in them by the viewer.

Attraction depends on authentic self-relevant situations (e.g., married Pam's rejection of a deliberate fidelit test). However, greater authenticity is not necessarily equated with more familiar environments. Fantasy settings added to the viewers' vicarious hedonic experience. However, a more accurate description of the peculiar situations that evoke the most positive viewing experiences must incorporate the combination of genuine goals and glamorous settings. In this way, the situational concept of the reality programming is successful when it is paradoxical (i.e., when it is and is not familiar, genuine, or accessible) and when viewers accept or assimilate the paradox, thereby negotiating a satisfying feeling of authenticity.

These processes of engagement are facilitated (and constrained) by the social and human aspects of the realityprogramming context, as well as by the physical environment, dramatic context, or plot. Thus, consumer agency is powerful in this context, but far from absolute. It is to these human dimensions that we now turn our attention.

\section{The Paradox of Identificatio}

The appeal of reality television has been attributed in part to the audience's desire to observe real people (Calvert 2000). Yet, the data suggest that some people may be more or less authentic as representations of the everyman. A paradox is revealed in which viewers negotiate the existence of both "people like me" and storybook "characters." To begin, Gina looks for sincerity of purpose in the Survivor cast:

Gina: The people were just more real on the firs show. And, sometimes the people on the second show just did stupid things. They were just dumb. I mean you know you are going to be out in the middle of the outback, and you're going to be given limited supplies. I would think you would try to fin a way to live a little bit better than they did, rather than worrying about who do I need to kick off. The whole focus was just screwed up. . . [Interviewer: When you say the other group was more real, what do you mean?] I mean that they were more real because some of them did not go into the show thinking that they were going to make a million dollars. I don't think they were as focused on the money or what was going to happen after the show. They didn't realize what was going to happen after the show, that there was going to be this huge thing, that they would be offered commercials and acting contracts and all that sort of thing.

Why is the original cast better than those who are atypically clever, prepared, or attractive? Perhaps because common people create a common understanding that facilitates the significatio of viewed acts. As de Certeau $(1984,2)$ states, 'The 'anyone' or 'everyone' is a commonplace, a philosophical topos. . . . Rather than being merely represented in it, the ordinary man acts out the text itself, in and by the text, and in addition he makes plausible the universal character of the particular place in which the mad discourse of a knowing wisdom is pronounced." Gina's comments illustrate elements of both psychodynamic and sociological conceptualizations of authentic identity. From a psychodynamic perspective, authenticity of self requires (1) a motivational core derived from needs for fulfillment (2) idealized goals, and (3) the talents necessary to make goal attainment possible (Ferrara 1998). In Gina's view, the authenticity of the survivors is in jeopardy due to a lack of talent, not motivation. From a sociological perspective, authentic identifi cation requires (1) possession of cultural roots, (2) a network of goals, and (3) participation in a socially recognized role. Thus, the cast becomes authentic as time passes and the culture of the group is formed and reinforced. As the show progresses, the survivors and their world become more authentic and self-relevant to Gina.

Engagement also emerges over time and requires some minimal level of concentrated exposure to the program elements. Thus, part of the process of engagement that was introduced in our discussion of the paradox of situation depends on the viewer's ability to make a personal connection with the human beings participating in the reality program.

Shirley: When you firs start watching Survivor, it's hard to get into it because you don't know the people. You don't know much about them. It gets more interesting once you get to know them; they tell you more about themselves, and that sort of thing. It took about three episodes, maybe longer than that. It took me awhile to figur out, when they were going back and forth between Ogakor and Kucha tribes. I couldn't keep it straight. After awhile it got a lot easier.

Interviewer: Did you have any people you liked or disliked?

Shirley: I didn't like Jerri. She's very controlling and argumentative. She had a big thing for Colby. That was funny. When we watched it last night, I thought it was interesting that she voted for Tina. I didn't think she was going to vote for Tina. I thought she had it bad for Colby. I think maybe she was kind of mad at him. . . . I liked Colby, because he was really hot. And I liked Tina and most all the people of Kucha, especially Alicia. I thought they were much more agreeable or pleasant to watch. Well, I didn't like Kimmi, the vegetarian.

Interviewer: Would the show have been better without people like Jerri? 
Shirley: It kind of made it interesting and made me want to watch to see if she was going to get kicked off. It didn't seem like anyone liked her.

Shirley could only begin to enjoy the show when she had learned enough about the participants to begin to defin the social relations among them. She also begins a process of definin herself through social comparison. She begins to identify with some players (e.g., Tina or Alicia) and to contrast herself with others (i.e., Kimmi, the vegetarian). Note that she also assumes that people who are like her on the surface (Jerri is a young, attractive, single woman, as is Shirley) must have a romantic attraction to Colby, the male player she describes as "hot." As learning about the social context continues, she interprets the social groups as oppositional. Kucha is good, while Ogakor is bad.

The tragic dramatic form with antagonist and protagonist is extremely ancient and may reflec deeply rooted Western cultural discourses regarding prototypical characteristics of social relations (Propp 1958). Thus, another level of identificatio involves group association and disassociation. Many of the reality programs have an implicit reliance on the sociological importance of community. Survivor especially makes this structural element explicit through the creation of opposing "tribes" whose members, early in the series, have to forge a common identity through shared goals. According to Muniz and O'Guinn (2001), members of communities necessarily possess (1) consciousness of kind, (2) shared rituals, and (3) a sense of duty to the group. In Survivor, castaways are lent consciousness of kind through an oppositional process largely driven by competitions with the other tribe (a common enemy). Tribe members share rituals through daily living and the game structure imposed by the producers that requires a ritualistic vote to determine who survives each episode. A sense of duty is fostered by the team competitions, the need to share scarce resources, and the communal problems of daily survival. The narrative structure of the program facilitates the development of community, provides the audience with the ability to identify both with communities and with individuals within communities, and contributes to the audience's experience of authenticity.

Evidence of identificatio at the individual or group level was not always prominent in the depth interviews. Shirley proved quite reticent during her interview and exhibited very little interest or emotion related to her reality program, Survivor. However, her journal entries, made in private, were much more revealing of the ultimate depth of her engagement with the players on the show. Her attachment to Rodger is evident in the extremely large print and emotionally laden statements. By the end of the Survivor II program, a disinterested and somewhat confused Shirley has transformed into a highly involved, active viewer who sincerely cares about the characters on the show.

Tonya demonstrated the process of identificatio at an extreme level when asked if she had a favorite character. She likened Rodger to her husband, from whom she was amicably divorced, saying, "I loved him [Rodger], because of the personal connection. When someone reminds me of someone who I've known in the past, whom I've had very positive feelings about, those feelings just expand, whether that's good or bad." Although Rodger may have been perceived as the most genuine person on Survivor II, it would be inaccurate to conclude that the presence of nonactors in ostensibly unscripted situations ensures positive audience response. Larry's journal reveals his appreciation for the cast of Survivor II, "hard bodies" who resemble actors more than "everyday people."

The paradox of identificatio concerns the juxtaposition of the ordinary and the extraordinary traits of the players in the reality dramas in the context of cultural discourses regarding the imperative of youth and beauty and personal life themes and goals. Zizek (1997) suggests that a similar oscillation between fantasy and reality constitutes true human desire and creates a conundrum, as the individual must negotiate "a fragile balance between the sublime image of the beloved and her real presence" (67). Larry cannot help but comment on the physical attractiveness of the Survivor II cast. Despite their uncommon beauty and the element of fantasy such beauty introduces, he feels that the attractive cast enhances the experience. Fantasy supports reality in that it provides the frame for the individual's "sense of reality" (Zizek 1997). At the same time, his favorite character and the one he identifie most closely with was Rodger, one of the least physically attractive players. As a Christian, Larry was impressed with the values Rodger displayed when he chose to bring a Bible to the outback. Rodger's compassionate and trustworthy behavior on the show only reinforced Larry's sense of identifica ion with him. Thus, Larry liked the beautiful people and the entertainment value they represented, but he identifie with the real person, the person whose values more closely matched his own. In this sense, the reality program provides a vehicle through which Larry's self-identity can be refined tested against others, and reinforced. Larry saw himself as like Rodger in terms of character, moral and religious convictions, and values. Rodger was well liked by the other survivors and also, importantly, by most viewers. Thus, Larry's self-concept was bolstered and affirme through this social comparison process.

Similarly, many of our informants expressed the sentiment that real people were desirable in television programming but that the meanings associated with extraordinary traits were highly valuable as well. Elizabeth liked Temptation Island because the singles reminded her of people she knows but found the show fun to watch because "everyone was so beautiful." Charles described Judy as being "like him," a conclusion that is particularly noteworthy as Charles is a young, African American male, and Judy is a 60 -yr.-old white woman. Clearly, the identifi cation process is based on more than simple surface-level similarity.

Akin to participants' enjoyment of atypically beautiful "characters," they also report an interesting perspective on 
disliked reality show cast members. Recall that Shirley did not wish to remove the disliked Jerri from Survivor. In everyday life, we may seek to avoid fractious or aggressive individuals, yet in the paradox of identity evidenced in reality television, the "bad guy" is a necessary part of the dramatic form. Disliked characters induce increased, rather than decreased, involvement. Consider, for example, Monica in her use of the Internet to facilitate engagement with The Mole:

Monica: I didn't like Charlie. He was probably the only character that I didn't like. Charlie was the bitter old man, the ex-detective. Every Wednesday night you could go online and ask questions of the person who was executed the night before. He was the only person I actually sat and listened to.

Similarly, when asked if he had contact with people like Jerri, Blake said, "I try not to," but later he made the following statement:

Blake: Without Jerri being annoying and, you know, Kimmie not eating everything. And then, you know, the slow people. Then it wouldn't be as entertaining as it would be. I mean, it's good to have. You know, it's sort of like wrestling - there are bad guys, you know. Or, let's see, not wrestling. I don't know why I brought that up. But, you know, you love to hate the bad guys.

After expressing a personal distaste for Jerri, both Gina and Shirley were asked if the show would have been better without her. The answer from both was an emphatic "no." Thus, although our viewers may have reacted as friends in watching their favorites, they clearly had an audience's appreciation for the role of the villain. In this way, authentic experience emerges from an experience tempered by (or structured as) narrative.

The ability of our viewers to negotiate a "dramatic cast" that contained both the everyman and the storybook heroes and villains comes through clearly in our data. Some postmodern theories characterize television as an intense and dynamic source of kaleidoscope-like images that leave the viewer bewildered, passive, and apathetic (Baudrillard 1983). However, the experiences of our viewers seem more akin to Kellner's (1992) assertion that "television and other forms of mass-mediated culture play key roles in the structuring of contemporary identity" and offer models for thought, behavior, and imitation.

For most informants in our study, a process of authenticity negotiation characterized their experience of the social aspects of reality television. As with the paradox of situation, the paradox of identificatio was resolved personally and uniquely by each viewer. However, a discussion of the negotiation process between the genuine and the factitious is incomplete without the introduction of meanings ascribed to the production/direction of the reality programs. It is to the resolution of this third paradox that we now turn our attention.

\section{The Paradox of Production}

One might argue that perceived authenticity (as a programming genre) is simply the lack of production, yet such a position ignores the more complex processes of signifi cation as it relates to the construction of authenticity. First, the symbolic requires the real. Zizek (1991) explains this relationship by suggesting that there can be no symbolic communication "without some 'piece of the real' to serve as a kind of pawn guaranteeing its consistency" (30). Second, "the real" is frequently not real at all but rather is spuriously produced. Zizek relates this to Lacan's concept of communication as a successful misunderstanding. However, this dilemma of the real is not an insurmountable hurdle to signification According to Zizek (1991), the crucial requisite is that our symbolic reality be perceived as found rather than produced. This suggests that viewers must trick themselves into a false perception of the program as unproduced ("life unscripted," as one cable channel touts). In fact, however, a different, more sophisticated picture emerges from the data as viewers fin significanc in the balance of the spontaneous with the produced. Confluen with this conceptualization, conflictin meanings associated with editing, casting, and producing were consistently evident in our participants' accounts. Similar to the resolution of the paradoxes of situation and identification viewers fin themselves seeking balance between the natural narrative and the manipulated narrative, the spontaneous and the scripted, and being and acting. Consider these excerpts from the interviews with Larry and Blake.

Interviewer: You said with the Real World that the camera shows you what the producers want you to see. Do you think they should just let the cameras run the whole time?

Larry: I think you have to have it edited, produced, and some stuff left out. I'm sure sometimes people don't always get a fair shake. But, I feel like that's the best way it could be done though, because nobody is going to watch $24 / 7$. If you see just an hour a week of somebody's life, that could be more exciting than seeing three days at a time in real time.

Interviewer: So there was an outlet there [at work] for people to share their opinions?

Blake: Yeah, we'd get into it. Of course, all the girls up there would be saying, "Oh Colby!" and the guys would be saying, "Elizabeth still looks good without makeup." As much as people complain about Jerri and all the people that were annoying [on Survivor], it definitel made the show better. And that's what the people who cast it planned, I'm sure. They thought, "This girl could be really annoying. I want to hit her right now. Let's put her on the show. Let's see how people react with her on the show, and then let's have the Texas guy and the student and the country bumpkin, that Rodger guy, and a girl who is bigger than all the guys on the show." They had a good mix of people who wouldn't be friends in real life. I don't think any of them would be friends, 
but that's what made the show cool. They put all these people together who had to stay there in order to win a million dollars and had to try to get along with each other. I thought that was pretty entertaining.

Thus, in these comments, we can see that-even in the depiction of real events - the story (and, inherently then, production) is important. Perhaps because, as de Certeau (1984) suggests, a story does not merely express practices or movements but rather makes them; to understand the story one must enter the movement oneself. Perhaps the closest reflectio of an authentic movement (a reality based on the degree of correspondence of the representation to the object represented) that can be transmitted in any context given the limits of technology is a $24 / 7$ video/audio feed, as is used in some Internet video camera sites. But, as Larry concluded, more empirical reality is not necessarily better. Some editing or manipulation of the raw material of what has been referred to as video vérité is desirable (Calvert 2000). Bazin (1967), a realist theorist of cinema, has argued that the producer or artist, by hiding the narrative or product of creation, can in fact create a reality perceived to be even more real than that produced by a simple recording (Williams 1973). From Bazin's (1967) perspective, "narrative must deny the time of its own telling-it must refuse its status as discourse (as articulation), in favor of its selfpresentation as simple identity, complete knowledge" (MacCabe 1976, 17). Thus, the tools of the cinematographer's trade may be used to enhance the reality of what is presented on screen so long as the elements of production are transparent from the viewer's perspective.

In Blake's view, an important part of the entertainment value of Survivor is the interesting mix of characters thrown together by the producers in a context sure to create conflic and challenge. A random selection of participants may not produce the same dramatic potential. The producer has the beneficen ability to add entertainment value through management of the casting process, editing the video facsimile of the players' behavior, and by choosing inherently interesting contexts and problems.

Interviewer: You said that the producers do this editing to make people more extreme. Would it be better to just let the cameras roll?

Gina: No, because then you've got Big Brother, and that was boring. I mean you've got to cut it so that what really happens is still there. But, some of the things you just want to cut, like the 2 hour raft segment (in Survivor II). They could have taken that 2 hours and put everything that happened in 30 minutes. It was too long; it was boring; it was just horrible.

Blake stated that it was good that producers could not control everything in Survivor, because total control implies a script and a loss of authenticity. Yet he also felt that the producers played an important role in generating suspense and conflic through casting and direct interventions, such as giving lavish rewards to a few lucky challenge winners. However, the producer's role in managing the meanings available for in- terpretation seemed to be appreciated as well. As Tonya pointed out, a fil producer "could take To Kill a Mockingbird and edit it to be a great movie or a piece of trash." In a similar vein, Gina viewed the producer's handling of the fina episode of Survivor II as undermining viewer interest in the show due primarily to the unnecessary length of the program.

Thus, we see a juxtaposition of contrivance and spontaneity that strongly influence viewer attraction. In trying to determine how reality is distinct from standard, scripted dramas or situational comedies, the authenticity of words emerged as paramount.

Interviewer: So you said an important part of the experience is feeling like you are a part of their real lives?

Tonya: Yeah, I almost transport myself into it and wonder how would I do in that situation. I would say, "What would I be able to do and how would I change the dynamic and how would I react to this situation?" I think about that a lot.

Interviewer: So, would that apply to a show like a daytime soap opera?

Tonya: No, it's just not them, so it's not as interesting to me . . . because I know even on Frasier, I'm sure those guys are funny, but someone is writing that stuff for them. That's not really them. Kelsey Grammar is not that funny. Someone wrote that stuff for him. It's just different. And if I'd found out halfway through that Survivor was scripted, I wouldn't have any interest in watching it. It's kind of like findin out that Milli Vanilli was lip-synching. Why buy their records? That's sort of the idea. That's why I think these reality shows are so interesting compared to a scripted show.

However, even inauthentic fare may be enjoyed for its own sake in the sense that irony and farce may be entertaining. Our reality television viewers were aware of the factitious aspects of the reality program experience. Yet, the observation that a cast member was being fake or acting rather than responding spontaneously did not necessarily destroy the entertainment value of the program. Consider this excerpt from Robin's interview.

Robin: The girls are all lined up on the beach, and the three guys are sitting there. They had flower that they would give to the girls that they chose for the fina date. Andy went before Kaya. When Andy didn't pick Megan, she wasn't at all surprised. But, when Kaya walked up and gave his flower to that other girl, you could just see the expression on her face, like, ahhh, not me? And then they filme her later all teary eyed and crying. It was just really funny . . . it's easy to cry, you know. I mean it really is. She shouldn't be a schoolteacher. I thought, "You could have been an actress."

A good example of this use of reality programming for ironic or farcical consumption (Thompson 2000) is found on the Internet at SurvivorSucks.com. On this site, a community of viewers takes turns posting caustic and comedic rants 
regarding the show they love to hate. Thus, another tactic for resolving the paradox of production is to approach the programming playfully. Common among our respondents such as Dan and Elizabeth or Calvin with his wife was the playful forecasting and critique of reality show participants' actions and decisions. Similarly, Shirley played the role of television critic when watching Survivor II. This practice of pretending or role-playing enabled viewers to extract considerable entertainment value from the programming, even when faced with paradoxical aspects of production. Approaching the text playfully or ironically facilitated the negotiation of the paradox of production and, therefore, eliminated potential threats to authentic experience.

Respondent accounts resonate with similar drives identifie in the realms of tourism where, for some categories of tourist, it is easy to accept a managed, front-stage tourism experience (Cohen 1988). Conversely, collectors espouse a more rigid source-based view of the authentic as based on the work of genuine artisans and noncommercial creative intent. Thus, from the perspective of some viewers, an important part of the authenticity negotiation process in the context of reality-based programming is to fin an interpretation of the producer's product that leads to a judgment of sufficien and satisfying authenticity. An authentic experience, then, becomes one from which the viewer can draw any number of personally satisfying meanings. The comparison of tourist versus collector perspectives may account for the schism between media criticism of the genre and ratings success. As pundits register a pejorative astonishment, reality programming increasingly dominates new show development. In the end, the tourists outnumber the collectors.

\section{DISCUSSION AND IMPLICATIONS}

Our analysis highlights a set of paradoxical elements that must be negotiated more or less successfully by viewers of reality television programming if a satisfyingly authentic experience is to be obtained. We now return to our theoretical model (depicted in fig 1) that focuses on the centrality of paradox to the production of satisfying authenticity. The model also provides a framework for answering the primary question that has guided our research effort. To reiterate, how does the consumption of reality television programming inform our understanding of the meaning of authenticity in a postmodern milieu?

First, if the reality television genre is perceived to resonate with authenticity, what process accounts for this resonance? Viewer responses, as illustrated by those respondents who had a positive experience in watching the show, were characterized by wondering. They wondered why the cast members acted or spoke as they did, they wondered what they would do if in the cast member's place, they wondered what the producers were "up to," they wondered about what actually happened and what might have been. Borrowing from Goffman (1966), we term this wondering "backstage thinking," and if we consider the program as a text, then this backstage thinking is evocative of a naive move toward deconstructionist textual critique. Viewer deconstruction of the program implies an engaged and interactive process within a postmodern milieu. Consumption of authenticity here is active discourse.

Second, data provided by our reality television viewers suggest an intriguing, seminal role of paradox in the active consumption of authenticity. We see this as the primary contribution of our research for two reasons. First, our results challenge the notion suggested by Trilling (1972) and adopted by others in the consumer research literature (Grayson and Shulman 2000) that authenticity necessarily depends on a judgment of genuineness. Although some connectedness to lived experience contributed positively to judgments of authenticity among our reality television viewers, these judgments were not consistent with a model of authenticity based on the indexicality of program elements. Viewers were as likely to value contrivance or fantasy in the construction of a satisfyingly authentic experience as they were to rely on connections to their personal reality. Indexicality in the context of reality television programming was an important condition for engagement but not sufficien to ensure a judgment of satisfying authenticity. Second, our data clearly revealed that the positive valuation component of authenticity (Trilling 1972) is a complex judgment based on the negotiation of paradoxical program elements. The degree of admiration accorded the reality television program depended on the viewer's ability to reconcile paradoxes of identificatio (beautiful people vs. "people like me"), situation (common goals vs. uncommon surroundings), and production (unscripted vs. necessary manipulation).

As such, neither the objectionable or enjoyable nature of the programming nor the indexicality of these elements adequately constitutes the viewer's judgment of authenticity. Rather, these elements are juxtaposed in a negotiation process that takes into account paradoxical elements of identification the program context or situation, and production decisions. Viewers who found the programming most satisfyingly authentic were those who reveled in the contradictory aspects of the genre. They experienced contradiction as resonant and engaging, rather than as bewildering or confusing. Often, this experience informed viewer responses to other reality programs (and other more diverse mass media messages) through a semiotic system of intertextuality in which the triumvirate of author, reader, and other texts interact. Ultimately, the observation of contradiction as engaging leads us to propose a causal role for paradox in judgments of authenticity in entertainment: viewers valued what we will call "contrived authenticity," or to slightly adjust Baudrillard's (1983) notion of hyperreality, "hyperauthenticity." Whereas hyperreality denotes the nonreflexiv substitution of signs of the real for the real itself, hyperauthenticity denotes viewers' reflexiv consumption of an individualized blend of fantasy with the real. Such viewers construct hyperauthenticity by blending indexical elements of programming that connect with their lived experiences and aspirations with fantastical or simulated elements that inspire their imaginations. Thus, reality shows may serve 
as utopian places where the viewer can engage in creative play space. Such practices mirror a similar type of utopic play observed by Kozinets (2001) in the Star Trek subculture and among Burning Man pilgrims (Kozinets 2002), and by Floch (1988) in retail servicescapes. This concept of utopic play also owes much to the notion of daydreaming that Campbell $(1987,84)$ describes as "a basic tension in imaginative hedonism between the pleasures of perfection and those of reality potential." However, while Campbell argues that consumers' dreams are made more pleasurable and authentic by deviating only modestly from some objective reality, we suggest that this process is not a compromise but rather an active negotiation of real and fantastic elements that leads to a constructed, authentic experience.

Finally, our work suggests that the existentialist notions of identity nonreflexivel achieved through practice (Heidegger 1926), originally introduced as a challenge to traditional modern perspectives of a core, recognizably authentic sense of self, now themselves need revisiting. Our viewers were quite aware of the factitious elements of the programming and practices observed on reality television and were aware of the paradoxical nature of the viewing experience. Viewers of reality television need not fin authenticity embedded in the programming text but rather coproduce it in order to consume a hyperauthentic product. This coproduction process can be considered a form of authenticating act or authoritative performance not unlike those observed in ritualized consumption (e.g., Wallendorf and Arnould 1991) or service encounter contexts (e.g., Arnould and Price 1993). As suggested by Cohen (1988) and echoed by Arnould and Price (2000), experience is not objectively real but rather endowed with authenticity by the individual. We extend this notion of the postmodern self as "constructed" (Arnould and Price 2000, 146) by showing how viewers endow their reality television viewing experience with authenticity through a reflexiv process of paradox negotiation. Our informants' accounts indicate that the production of hyperauthenticity need not be hindered by self-conscious negotiation of paradoxical elements of the programming. Viewers are able to extract self-authenticating meanings despite the obvious flatness routinization, and commodificatio of the reality programming context (Handler and Saxton 1988).

In a similar vein, Kellner $(1992,153)$ speculated that "postmodern identity tends more to be constructed from the images of leisure and consumption and tends to be more unstable and subject to change." In support of the notion that television contributes powerfully to consumers' perceptions of reality, O'Guinn and Shrum $(1997,290)$ argued that "passive learning, coupled with the impact of accessibility on judgment, is strongly implicated in this social construction effect." We agree that television contributes significantl to the construction of social reality but believe that the effect is more than incidental, at least in the context of reality programming. Our informants were without exception cognizant of the producers' control of discourse provided in reality programming. Further, while we ob- served no evidence of identity change in the accounts of our informants, our reality television viewers used the images, props, actors, and practices depicted in programming as a testing board for their self-identities and social identities. It is possible that some identity dynamics would be observable if viewers and their viewing practices were studied over a longer period of time.

De Certeau (1984, 187) concluded, "Today, fictio claims to make the real present, to speak in the name of facts and thus to cause the semblance it produces to be taken as referential reality. Hence those to whom these legends are directed (and who pay for them) are not obliged to believe what they don't see (a traditional position), but rather to believe what they see (a contemporary position)." However, our informants' accounts suggest an alternative interpretation of the postmodern television viewing experience. From paradox negotiation comes paradox - we accept as authentic the fantasy that we coproduce.

\section{[Dawn Iacobucci served as editor and Eric Arnould served as associate editor for this article.]}

\section{REFERENCES}

Abelman, Robert (1998), Reaching a Critical Mass: A Critical Analysis of Television Entertainment, Mahwah, NJ: Lawrence Erlbaum.

Arnould, Eric J. and Linda L. Price (1993), "River Magic: Hedonic Consumption and the Extended Service Encounter," Journal of Consumer Research, 20 (June), 24-45.

(2000), "Authenticating Acts and Authoritative Performances," in The Why of Consumption: Contemporary Perspectives on Consumers' Motives, Goals, and Desires, ed. S. Ratneshwar, David Glen Mick, and Cynthia Huffman, New York: Routledge, 144-63.

Baudrillard, Jean (1983), Simulations, New York: Semiotexte.

Bazin, Andre (1967), What Is Cinema? Berkeley: University of California Press.

Boorstin, Daniel (1961), The Image: A Guide to Pseudo-Events in America, New York: Harper.

Bork, Robert H. (1996), Slouching towards Gomorrah, New York: Harper.

Bourdieu, Pierre (1980), "The Aristocracy of Culture," Media, Culture, and Society, 2 (3), 225-54.

Calvert, Clay (2000), Voyeur Nation: Media, Privacy, and Peering in Modern Culture, Boulder, CO: Westview.

Campbell, Colin (1987), The Romantic Ethic and the Spirit of Modern Consumerism, Oxford: Blackwell.

Celsi, Richard L., Randall L. Rose, and Thomas W. Leigh (1993), "An Exploration of High-Risk Leisure Consumption through Skydiving," Journal of Consumer Research, 20 (June), 1-23.

Cohen, Erik (1979), "Rethinking the Sociology of Tourism," Annals of Tourism Research, 6 (1), 18-35.

- (1988), "Authenticity and Commoditization of Tourism," Annals of Tourism Research, 15 (4), 371-86.

Cornet, Joseph F. S. (1975), "African Art and Authenticity," African Arts, 9 (October), 52-55.

de Certeau, Michel (1984), The Practice of Everyday Life, Berkeley: University of California Press.

Deighton, John (1992), "The Consumption of Performance," Journal of Consumer Research, 19 (December), 362-72. 
Deighton, John, Daniel Romer, and Josh McQueen (1989), "Using Drama to Persuade," Journal of Consumer Research, 16 (December), 335-43.

Feifer, Michelle (1985), Going Places, London: Macmillan.

Ferrara, Alessandro (1998), Reflectiv Authenticity, London: Routledge.

Firat, A. Fuat and Alladi Venkatesh (1995), "Liberatory Postmodernism and the Reenchantment of Consumption," Journal of Consumer Research, 22 (December), 239-67.

Floch, Jean-Marie (1988), "The Contribution of Structural Semiotics to the Design of a Hypermarket," International Journal of Research in Marketing, 4 (3), 233-52.

Gabler, Neal (1998), Life: The Movie; How Entertainment Conquered Reality, New York: Knopf.

Goffman, Erving (1966), Behavior in Public Places: Notes on the Social Organization of Gatherings, Glencoe, IL: Free Press.

Grayson, Kent and David Shulman (2000), "Indexicality and the Verificatio Function of Irreplaceable Possessions: A Semiotic Analysis," Journal of Consumer Research, 27 (June), 17-30.

Handler, Richard and William Saxton (1988), "Dyssimulation: Reflexivit , Narrative, and the Quest of Authenticity in 'Living History," Cultural Anthropology, 3 (3), 242-60.

Hedges, Ken (1997), Fibers and Forms: Native American Basketry of the West, San Diego, CA: San Diego Museum of Man.

Heidegger, Martin (1926/1962), Being and Time, New York: Harper.

Kellner, Douglas (1992), "Popular Culture and the Construction of Postmodern Identities," in Modernity and Identity, ed. Scott Lash and Jonathan Friedman, Oxford: Blackwell, 141-77.

Kozinets, Robert V. (2001), "Utopian Enterprise: Articulating the Meanings of Star Trek's Culture of Consumption, Journal of Consumer Research, 28 (June), 67-88.

- (2002), "Can Consumers Escape the Market? Emancipatory Illuminations from Burning Man," Journal of Consumer Research, 29 (June), 20-38.

MacCabe, Colin (1976), "Theory and Film: Principles of Realism and Pleasure," Screen, 17 (Winter), 7-27.
Muniz, Albert, Jr., and Thomas C. O’Guinn (2001), "Brand Community," Journal of Consumer Research, 27 (March), 412-32.

O'Guinn, Thomas C. and L. J. Shrum (1997), "The Role of Television in the Construction of Consumer Identity," Journal of Consumer Research, 23 (March), 278-94.

Orvell, Miles (1989), The Real Thing: Imitation and Authenticity in American Culture, 1880-1940, Chapel Hill: University of North Carolina Press.

Propp, Vladimir I. (1958), Morphology of the Folktale, ed. Svatava Pirkova-Jakobson, Bloomington: Indiana University Press.

Ritson, Mark and Richard Elliot (1999), "The Social Uses of Advertising: An Ethnographic Study of Adolescent Advertising Audiences," Journal of Consumer Research, 26 (December), 260-77.

Stern, Barbara B. (1994), "Authenticity and the Textual Persona: Postmodern Paradoxes in Advertising Narrative," International Journal of Research in Marketing, 11 (September), $387-400$.

Thompson, Craig J. (2000), "Postmodern Consumer Goals Made Easy!!!!" in The Why of Consumption: Contemporary Perspectives on Consumer Motives, Goals, and Desires, ed. S. Ratneshwar, David Glen Mick, and Cynthia Huffman, New York: Routledge, 121-39.

Trilling, Lionel (1972), Sincerity and Authenticity, Cambridge, MA: Harvard University Press.

Urry, John (1990), The Tourist Gaze: Leisure and Travel in Contemporary Societies, London: Sage.

Wallendorf, Melanie and Eric J. Arnould (1991), "“We Gather Together': The Consumption Rituals of Thanksgiving Day," Journal of Consumer Research, 18 (June), 13-31.

Widdicombe, Sue and Rob Wooffit (1990), “'Being' versus 'Doing' Punk: On Achieving Authenticity as a Member,' Journal of Language and Social Psychology, 9 (4), 257-77.

Williams, Christopher (1973), "Bazin on Neo-Realism," Screen, 14 (Winter), 61-68.

Zizek, Slavoj (1991), Looking Awry: An Introduction to Jacques Lacan through Popular Culture, Cambridge, MA: MIT Press. (1997), The Plague of Fantasies, London: Verso. 